\title{
Structure of Hybrid Interpolymeric Complexes of Polyvinyl Alcohol and Halides of Second Group Elements
}

\author{
I. Yu. Prosanov ${ }^{1}$ and E. Benassi ${ }^{2,3}$ \\ ${ }^{1}$ Institute of Solid State Chemistry and Mechanochemistry, Novosibirsk, Russia \\ ${ }^{2}$ School of Science and Technology, Nazarbayev University, Astana, Kazakhstan \\ ${ }^{3}$ Novosibirsk State University, Novosibirsk, Russia \\ Correspondence should be addressed to I. Yu. Prosanov; prosanov@mail.ru
}

Received 16 March 2017; Revised 4 August 2017; Accepted 12 September 2017; Published 16 October 2017

Academic Editor: Luigi Nicolais

Copyright (c) 2017 I. Yu. Prosanov and E. Benassi. This is an open access article distributed under the Creative Commons Attribution License, which permits unrestricted use, distribution, and reproduction in any medium, provided the original work is properly cited.

Density functional theory was used to investigate structure and properties of polyvinyl alcohol complexes with halides of second group elements $\mathrm{XHal}_{2}(\mathrm{X}=\mathrm{Be}, \mathrm{Mg}, \mathrm{Ca}, \mathrm{Zn}, \mathrm{Sr}, \mathrm{Cd}, \mathrm{Ba}$, and $\mathrm{Hg}$; $\mathrm{Hal}=\mathrm{F}, \mathrm{Cl}, \mathrm{Br}$, and $\mathrm{I}$ ). PVA can form hybrid interpolymeric complexes with some of them. These complexes show double spiral structure of two types.

\section{Introduction}

Polyvinyl alcohol (PVA) is a well-known complexing polymer [1]. In our previous works [2-6] it has been shown that PVA can form hybrid interpolymeric complexes with some insoluble inorganic compounds. In these complexes the inorganic components form chain structures, which is rather unusual for them. Experimental investigation of such compounds' structure is a challenge due to their noncrystallinity. Quantum chemical methods provide reliable and useful tools to explore the electronic structure and predict properties, amongst which, for instance, UV-Vis absorption spectra. Complexes of PVA with hydroxides are rather challenging to model because of the presence of different types of hydrogen bonding, coordinative bonding, and their combinations. Halide systems are simpler in this respect. Only one type of coordinative bonding usually is shown. It is, therefore, easier to attribute some spectroscopic characteristics to specific structural features in this case and individuate them in more complicated systems. Most of the chosen halides are highly soluble in water; this allows easily producing the desired hybrid materials. Complexes with insoluble inorganic compounds may be produced from the formers through a technique previously developed in the solid state chemistry [7]. Examples of such approach to PVA- $\mathrm{Zn}(\mathrm{OH})_{2}$, PVA-CuO,
PVA-SnO $2, \mathrm{PVA}^{-\mathrm{TiO}_{2}}$, and PVA-CdS complexes production may be found in $[2-6,8,9]$. Compounds of second group elements have variety of applications. Therefore, there is a need in materials based on them. It can be stated that complexes with soluble inorganic compounds can serve as convenient model systems for the investigation of hybrid interpolymeric complexes. Moreover, quantum mechanical data about their structure are crucial for a planning of further synthesis. The main object of the present research is to computationally investigate the possibility of hybrid interpolymeric complexes formation between PVA and halides of second group elements (from $\mathrm{Be}$ to $\mathrm{Hg}$ ) and predict their properties. This, therefore, represents an initial phase of a wider research project. In further research, we shall use these computational results as starting point for the designing experimental work, and we shall compare computed and experimentally determined properties, as done, for example, in [10].

Capability of X-ray diffraction techniques for noncrystalline materials structure determination is limited. One of the main goals of the present study is, therefore, the computational prediction of the structure of the investigated compounds at molecular level; to do that, we accounted for recommendations [12]. In order to choose the most appropriate level of theory, we need to remind that post-Hartree-Fock 
ab initio methods, such as Coupled-Cluster theory (CC), second- and fourth-order Møller-Plesset perturbation theory (MP2 and MP4), or quantum chemistry composite methods (Gaussian- $n, \mathrm{CBS}, \mathrm{Wn}$, etc.) are well-known to provide high accuracy ground state molecular geometries. However, due to their extremely high computational cost, these methods are inapplicable to systems of such a large size, as those under investigation. We have therefore chosen to have an estimation of the structural characteristics of the studied compounds via geometry optimization at density functional theory (DFT), whose computational costs are significantly less with respect to those aforementioned and whose results concerning the geometry are usually in good agreement with the experimental X-ray diffraction data. An example in the literature that proves the adequacy of a DFTbased approach for analogue hybrid systems is represented by calculations used for the determination of PVA-iodine complex structure [13]. As known, the quality of the DFT results depends on the choice of the functional and of the basis set, which is usually determined after benchmarking or for analogy with respect to compounds previously investigated in the literature. In our case, both these ways are impossible, since on the one side we do not have access to the experimental data of reference (as mentioned above) and on the other side there are no similar compounds already studied in the literature from a computational point of view. We have therefore decided to investigate the structure and the geometrical characteristics of these hybrid interpolymeric complexes by employing popular, standard, not very refined, albeit fairy sound approach. We are aware that we should not give too much importance to the absolute values of our findings, but rather to the general trends that our results draw.

\section{Description of Models}

We systematically explored the adsorption of any of the thirty-two halides of second group elements, $\mathrm{XHal}_{2}(\mathrm{X}=$ alkaline earth metals (group 2) and volatile metals (group 12); $\mathrm{Hal}=$ halogens), with PVA. For modeling hybrid materials, $\left[x\right.$ PVA $\cdot n \mathrm{XHal}_{2}$ ], we build PVA fragments consisting of $x$ $=3.5$ to 11.5 PVA units and a 6 -unit halide chain $(n=6)$ adsorbed on it. The number of units was large enough to consider negligible on the investigated properties the effects due to the lack of periodic boundary conditions. The choice of $x$ was determined by the length of the 6 -unit halide chain. The two components of the hybrid materials (namely, the halide chain and PVA) were also separately studied.

\section{Computational Details}

The ground state optimized geometries of hybrid compounds and their components were obtained using density functional theory (DFT) level in the gas phase. In the triple- $\zeta$ basis sets of Ahlrichs and coworkers Def2-TZVP [14] was used for all elements except $\mathrm{Cd}$ and $\mathrm{Hg}$, for which the double$\zeta$ LANL2DZ coupled with the LANL2DZ effective core potential [15] was employed. Two different hybrid-GGA exchange-correlation functionals were used, namely Becke three-parameter Lee-Yang-Parr (B3LYP) [16] and PBE0 [17].
These functionals are widely acknowledged as good choices for structural predictions. They were tested both without and with the inclusion of the D3 version of Grimme's semiempirical dispersion with Becke-Johnson damping GD3BJ [18]. Optimized geometries were subsequently submitted to frequencies calculation in harmonic approximation, in order to check whether the potential energy surface minima were "genuine" and to compute the thermochemical properties. No imaginary frequencies were found. IR intensities and Raman activities were also contextually computed.

In order to check the possible issues caused by the basis set superposition error (BSSE), we also included counterpoise corrections $[19,20]$. We did rerun the aforementioned tasks for the halide-PVA complexes, at B3LYP[+GD3BJ] level. The system was partitioned in two subfragments (halide and PVA). No remarkable change was noticed with respect to the standard calculation. To investigate the presence and nature of halide-PVA interactions, two different approaches were used: (1) topological analysis based on Bader's atoms in molecules (AIM) theory [21-23] and (2) the covalent interaction (NCI) index combined with the second derivative of the reduced density gradient along the second main axis of variation [24-27]. B3LYP[+GD3BJ] geometries and electron densities were used for this purpose. Solvent effects were taken into account via the implicit polarizable continuum model in its integral equation formalism (IEF-PCM) [28] with radii and nonelectrostatic terms for Truhlar and coworkers' SMD solvation model [29]. The standard values for dielectric constant and refractive index were always assumed (solvent $=$ ethanol). B3LYP $[+$ GD3BJ] geometries and electron densities were used for this purpose.

Two-electron integral accuracy was set to $10^{-12}$. Integration grid for the electronic density topological and RDG analyses was set to 150 radial shells and 974 angular points. In other cases integration grid was set as 99 radial shells and 590 angular points. Convergence criteria of Self-Consistent Field was set to $10^{-12}$ for root mean square (RMS) change in density matrix and $10^{-10}$ for maximum change in density matrix. Convergence criteria for optimizations were set to 2 $\times 10^{-6}$ a.u. for maximum force, $1 \times 10^{-6}$ a.u. for RMS force, $6 \times 10^{-6}$ a.u. for maximum displacement, and $4 \times 10^{-6}$ a.u. for RMS displacement. All calculations were performed using GAUSSIAN G09.D01 package [30]. The location of BCPs and subsequent calculation of SF values were performed using a modified version of the PROAIMV program [31-33]. The calculation of the RDG and its derivatives was performed using homemade code.

\section{Results and Discussion}

Hereafter we summarize our findings.

(1) The results obtained at different levels of theory are in reciprocal agreement, providing the same trends. Solvent effects are negligible concerning both the differences in thermochemical quantities (due to compensation effects) and the structural properties.

(2) The chain structure is a metastable state for $\mathrm{XHal}_{2}$ $(\mathrm{X}=\mathrm{Be}, \mathrm{Mg}, \mathrm{Ca}, \mathrm{Zn}, \mathrm{Sr}, \mathrm{Cd}, \mathrm{Ba}$, and $\mathrm{Hg}$; Hal 


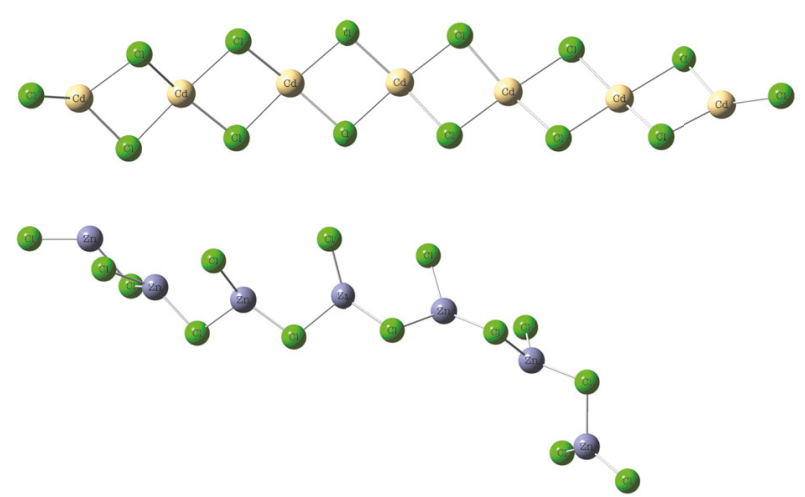

FIGURE 1: Examples of the two types of inorganic polymeric structures adsorbed on PVA. Organic portion is not shown for the sake of clarity.

$=\mathrm{F}, \mathrm{Cl}, \mathrm{Br}$, and I). Exceptions are represented by mercury chloride and iodide, which do not come to a polymeric state from all initial arrangements which we tried. Initially lined set of halide molecules rearranges into the resulting chain structure with metal ions in a distorted tetrahedral coordination. Adjacent tetrahedrons with halide ions in their corners are connected through their edges. The aforementioned halides can therefore be produced in polymeric form if a proper initial arrangement will be created. We suggest the usage of PVA as a template for such initial arrangement. This complexing polymer can adsorb halides' molecules on its linear chain and provide condition for their further polymerization.

(3) Halides adsorbed on PVA form inorganic chains except mercury halides. There are two types of such chains: with one or two bridge halide atoms (Figure 1). We deduce interpolymeric structure of the whole PVA-halide complex from the portion of optimized structure which is locally linear.

(4) The interpolymeric complexes have a double spiral form.

(5) Bonding energies of the complexes and inorganic polymeric chains are summarized in Table 1 , where $H_{\text {Single }}$ denotes the bonding enthalpy of single $\mathrm{XHal}_{2}$ molecule absorbed on PVA, $H_{\text {Polcomp }}$ denotes the bonding enthalpy of PVA-XHal ${ }_{2}$ interpolimeric complex, and $H_{\text {Chain }}$ denotes the bonding enthalpy in $\mathrm{XHal}_{2}$ polymeric chain. These values are given in $\mathrm{eV}$ unites per $\mathrm{XHal}_{2}$ unit. The signs are changed from negative to positive. The values $H_{\text {Cryst }}$ and $H_{\text {Dim }}$ are also reported for the comparison purposes. The former is defined as the sum of crystallization and evaporation enthalpies for the corresponding compound according to [11]. The latter corresponds to the bonding energy of $\mathrm{XHal}_{2}$ dimers (with changed sign). Periods of inorganic components of interpolymeric complexes $(T)$ are also represented in the table as well. The shown data refer to DFT B3LYP[GD3BJ] level of theory.
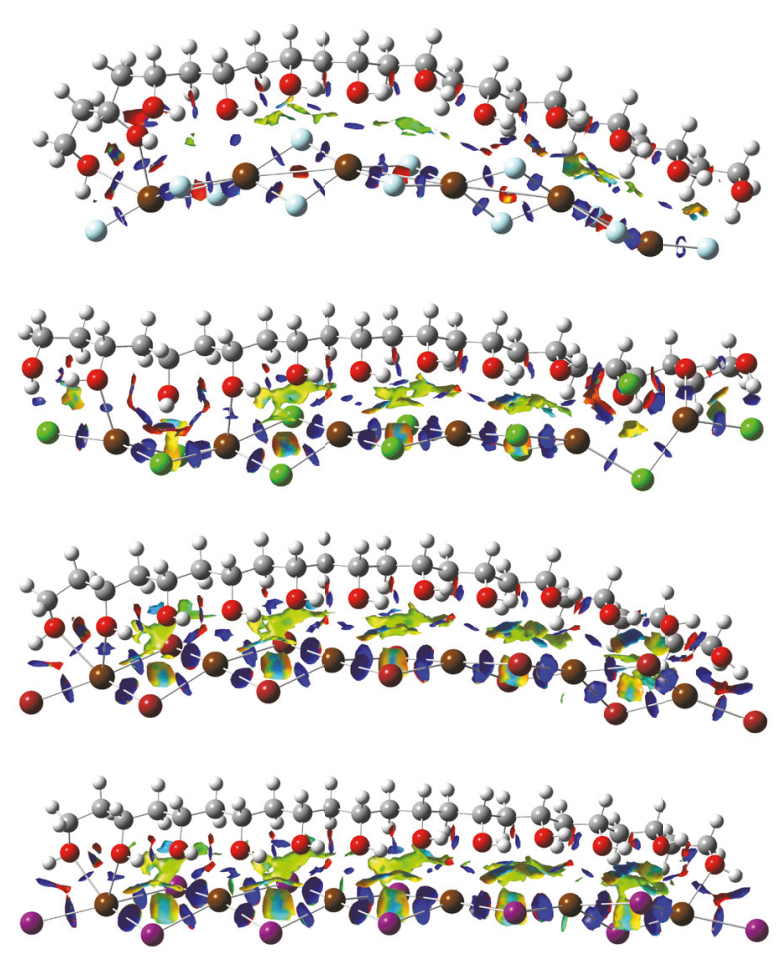

FIGURE 2: Plots of the NCI isosurfaces ( $s=0.5$ a.u. and a blue-greenred color scale from -0.01 a.u. $<\operatorname{sign}\left(\lambda_{2}\right) \rho(r)<+0.01$ a.u.) for $[1$ PVA $\left.\cdot n \mathrm{BaHal}_{2}\right]$. White: hydrogen, grey: carbon, red: oxygen, dark brown: barium, light blue: fluorine, green: chlorine, light brown: bromine, and purple: iodine.

These data indicate that a bonding energy for a crystal structure is higher than a bonding energy for a polymeric structure for all compounds (except $\mathrm{ZnBr}_{2}$ ), as expected. Some compounds have bonding energy of single $\mathrm{XHal}_{2}$ molecule with PVA higher than bonding energy for crystal structure. Moreover, some compounds $\left(\mathrm{BeBr}_{2}, \mathrm{CaF}_{2}, \mathrm{CaBr}_{2}, \mathrm{ZnF}_{2}, \mathrm{ZnCl}_{2}\right.$, and $\mathrm{ZnBr}_{2}$ ) have bonding energy of interpolymeric complex higher than bonding energy for crystalline state. Evidently, such systems are especially suitable for interpolymeric complexes production due to their possible thermodynamic stability. Some interpolymeric complexes have bonding energy higher than that for dimers. Dimerization can be regarded as an initial step of crystallization. Polymerization can, therefore, be more preferable way than crystallization and it is expected that the production of metastable polymeric structures from the solutions of the corresponding systems can be carried out.

(6) The RDG analysis shows extended regions of nonbonding interaction between PVA and the inorganic moiety (Figure 2, colored in green. In the example, we consider barium complexes; similar behavior is observed for other metals). These regions increase their extension passing from $\mathrm{Hal}=\mathrm{F}$ to $\mathrm{I}$ (more expanded orbitals). We also observe more localized regions of strong attractive (bonding) interaction, 
TABLE 1

\begin{tabular}{|c|c|c|c|c|c|c|}
\hline & $H_{\text {Single }}, \mathrm{eV}$ & $H_{\text {PolComp }}, \mathrm{eV}$ & $H_{\text {Cryst }}, \mathrm{eV}[11]$ & $H_{\text {Chain }}, \mathrm{eV}$ & $H_{\text {Dim }}, \mathrm{eV}$ & $T, \AA$ \\
\hline $\mathrm{BeF}_{2}$ & 1.8 & 2.1 & 2.3 & 1.7 & 2.0 & 2.2 \\
\hline $\mathrm{BeCl}_{2}$ & 2.0 & 0.94 & 1.3 & 0.76 & 0.86 & 3.2 \\
\hline $\mathrm{BeBr}_{2}$ & 1.9 & 1.3 & 1.2 & 0.82 & 0.89 & 3.1 \\
\hline $\mathrm{BeI}_{2}$ & 1.9 & 0.68 & 1.0 & 0.43 & 0.55 & 3.9 \\
\hline $\mathrm{MgF}_{2}$ & 2.2 & 3.3 & 3.5 & 2.6 & 3.0 & 2.9 \\
\hline $\mathrm{MgCl}_{2}$ & 2.4 & 2.0 & 2.2 & 1.4 & 1.7 & 3.6 \\
\hline $\mathrm{MgBr}_{2}$ & 2.4 & 2.2 & 3.0 & 1.6 & 1.8 & 3.6 \\
\hline $\mathrm{MgI}_{2}$ & 1.9 & 1.2 & 1.6 & 1.0 & 1.1 & 4.8 \\
\hline $\mathrm{CaF}_{2}$ & 2.1 & 3.9 & 3.5 & 3.0 & 3.6 & 3.5 \\
\hline $\mathrm{CaCl}_{2}$ & 2.4 & 2.6 & 2.6 & 1.8 & 2.2 & 4.2 \\
\hline $\mathrm{CaBr}_{2}$ & 2.3 & 2.9 & 2.5 & 1.9 & 2.3 & 4.3 \\
\hline $\mathrm{CaI}_{2}$ & 2.0 & 1.8 & 2.3 & 1.4 & 1.7 & 4.5 \\
\hline $\mathrm{ZnF}_{2}$ & 2.1 & 2.6 & 2.4 & 1.93 & 2.1 & 2.9 \\
\hline $\mathrm{ZnCl}_{2}$ & 1.9 & 1.4 & 1.3 & 0.94 & 0.97 & 3.6 \\
\hline $\mathrm{ZnBr}_{2}$ & 1.9 & 1.7 & 1.3 & 1.3 & 1.4 & 3.6 \\
\hline $\mathrm{ZnI}_{2}$ & 1.0 & 0.43 & 1.4 & 0.50 & 0.53 & 4.2 \\
\hline $\mathrm{SrF}_{2}$ & 1.6 & 2.7 & 3.7 & 2.3 & 2.8 & 3.8 \\
\hline $\mathrm{SrCl}_{2}$ & 1.7 & 2.2 & 2.7 & 1.7 & 2.1 & 4.3 \\
\hline $\mathrm{SrBr}_{2}$ & 1.7 & 2.0 & 2.5 & 1.7 & 1.9 & 4.5 \\
\hline $\mathrm{SrI}_{2}$ & 1.8 & 1.9 & 2.2 & 1.4 & 1.7 & 4.3 \\
\hline $\mathrm{CdF}_{2}$ & 0.97 & 1.5 & 2.6 & 1.1 & 1.2 & 3.4 \\
\hline $\mathrm{CdCl}_{2}$ & 0.86 & 0.83 & 1.6 & 0.67 & 0.64 & 3.8 \\
\hline $\mathrm{CdBr}_{2}$ & 0.83 & 0.59 & 1.4 & 0.59 & 0.57 & 3.9 \\
\hline $\mathrm{CdI}_{2}$ & 0.70 & 0.39 & 1.5 & 0.48 & 0.48 & 4.3 \\
\hline $\mathrm{BaF}_{2}$ & 1.7 & 2.5 & 3.0 & 2.1 & 2.6 & 4.0 \\
\hline $\mathrm{BaCl}_{2}$ & 1.8 & 2.1 & 2.7 & 1.7 & 2.1 & 4.6 \\
\hline $\mathrm{BaBr}_{2}$ & 1.8 & 2.0 & 2.7 & 1.6 & 1.9 & 4.8 \\
\hline $\mathrm{BaI}_{2}$ & 1.6 & 1.9 & - & 1.4 & 1.8 & 5.0 \\
\hline
\end{tabular}

between some oxygen atoms and the metal (Figure 2, colored in blue). There exist also weak attractive interactions between hydrogen atoms of the hydroxyl groups of PVA with halogen atoms (Figure 2, colored in turquoise). These findings confirm the stabilization of the interpolymeric complexes.

(7) Although the obtained results look reasonable and feasible, we should not forget about the complexity of the experimental problem. In this study we built some sound structural models, but there is a reason to suppose that in such complexes each inorganic molecule actually may interact with two PVA chains, as is represented in [1]. For instance, calculations for PVA- $\mathrm{ZnCl}_{2}$ and PVA-CdCl${ }_{2}$ complexes give bonding energies of about 1.4 and $0.83 \mathrm{eV}$, respectively, instead of 1.7 and $1.0 \mathrm{eV}$ [1] (error -20\%). Unfortunately, DFT calculations for [2 PVA $\left.\cdot n \mathrm{XHal}_{2}\right]$ cannot be coped with the available computational resources; furthermore, it might be questionable whether LBS DFT methods are still applicable to predict the structure and properties of so large systems. It is possible that $\left[1 \mathrm{PVA} \cdot n \mathrm{XHal}_{2}\right]$ and $\left[2 \mathrm{PVA} \cdot n \mathrm{XHal}_{2}\right]$ represent the two extremal models for the experimental structure. Knowledge of complexes' stoichiometry is needed for the more precise determination of the calculations accuracy, which shall be the matter of further investigations.

\section{Conclusions}

We systematically investigated the complexation of PVA with halides of second group elements by mean of DFT calculations, performed at different levels of theory. Halides of many second group elements have metastable polymeric form, which can be stabilized by complexation with PVA or other organic polymers. RDG analysis confirms thermodynamical data showing intramolecular interactions between PVA and the inorganic moiety. Hybrid interpolymeric complexes in a form of double spiral are suggested as ground or metastable state configurations in majority of the cases. Some of them can be produced from the solutions of the correspondent mixtures. The existence of two different types of polymeric inorganic halides was predicted to show different Raman spectra. In one type, all halide ions are equal and each of them plays the role of bridge between two cations. In the other type, there are two different anions: one is a bridge between two cations and the other has a lateral location. With respect 
to the PVA spectrum, an additional Raman-active mode is, subsequently, expected in the former case ("breathing" mode) and two modes in the latter case. Representatives of the first type structures are cadmium halides. Their properties were studied in detail in [10] and observed Raman spectra were found in agreement with prediction. Representatives of the second type structures are zinc halides. Our unpublished data testify for the concordance between prediction and observations in this case as well. The obtained results will serve as a reference for the investigation of more complicated systems, such as, for example, complexes with halides of transition metals, hydroxides, oxides, and chalcogenides. The optimized structures may be useful templates as initial guesses for the modeling of the structural properties. They may also help to design new compounds and to plan their investigation. For instance, our results indicate that zinc halides are the most promising candidates for the synthesis of hybrid interpolymeric complexes.

\section{Conflicts of Interest}

The authors declare that there are no conflicts of interest regarding the publication of this paper.

\section{Acknowledgments}

The Siberian Branch of the Russian Academy of Sciences (SB RAS) Siberian Supercomputer Center is gratefully acknowledged for providing supercomputer facilities. E. Benassi expresses his gratitude to NSU and 5-100 Excellence Programme of Russian Ministry of Science and Education.

\section{References}

[1] S. N. Ushakov, Polyvinyl Alcohol and Its Derivatives, vol. 1, Academy of Sciences of the USSR, Moscow, Russia, 1960 (Russian).

[2] I. Y. Prosanov, N. V. Bulina, and Y. A. Chesalov, "Hybrid material polyvinyl alcohol-copper oxide and its electrical properties," Physics of the Solid State, vol. 54, no. 8, pp. 1699-1703, 2012.

[3] I. Y. Prosanov, N. V. Bulina, and K. B. Gerasimov, "Complexes of polyvinyl alcohol with insoluble inorganic compounds," Physics of the Solid State, vol. 55, no. 10, pp. 2132-2135, 2013.

[4] I. Y. Prosanov, "Complex compound polyvinyl alcohol-titanic acid/titanium dioxide," Physics of the Solid State, vol. 55, no. 2, pp. 450-453, 2013.

[5] I. Y. Prosanov, Y. A. Chesalov, K. B. Gerasimov, and N. V. Bulina, "Hybrid material polyvinyl alcohol-stannic acid/stannic oxide," Physics of the Solid State, vol. 55, no. 7, pp. 1519-1524, 2013.

[6] I. Y. Prosanov and N. V. Bulina, "Polymeric sulfides CdS, CuS, and NiS in polyvinyl alcohol matrix," Physics of the Solid State, vol. 56, no. 6, pp. 1270-1272, 2014.

[7] A. R. West, Solid State Chemistry and Its Applications, John Wiley and Sons, Oxford, UK, 1984.

[8] W. Sang, Y. Fang, J. Fan, Y. He, J. Min, and Y. Qian, "Novel synthesis method of $\mathrm{ZnO}$ nanorods by ion complex transformed PVA-assisted nucleation," Journal of Crystal Growth, vol. 299, no. 2, pp. 272-276, 2007.

[9] A. Reza Hajipour, F. Mohammadsaleh, and M. Reza Sabzalian, "Copper-containing polyvinyl alcohol composite systems:
Preparation, characterization and biological activity," Journal of Physics and Chemistry of Solids, vol. 83, pp. 96-103, 2015.

[10] I. Y. Prosanov, E. Benassi, N. V. Bulina, and A. A. Matvienko, "Structure and properties of self-assembling low-dimensional hybrid materials: the case of cadmium halides in polyvinyl alcohol," Current Inorganic Chemistry, vol. 7, no. 3, pp. 155-161, 2017.

[11] I. S. Grigoriev and E. Z. Meilikhov, Handbook of Physical Quantities, CRC Press, Boca Raton, Fla, USA, 1995.

[12] M. Sierka, "Synergy between theory and experiment in structure resolution of low-dimensional oxides," Progress in Surface Science, vol. 85, no. 9-12, pp. 398-434, 2010.

[13] T. Takahama, S. M. Saharin, and K. Tashiro, "Details of the intermolecular interactions in poly(vinyl alcohol)-iodine complexes as studied by quantum chemical calculations," Polymer (United Kingdom), vol. 99, pp. 566-579, 2016.

[14] F. Weigend and R. Ahlrichs, "Balanced basis sets of split valence, triple zeta valence and quadruple zeta valence quality for $\mathrm{H}$ to Rn: design and assessment of accuracy," Physical Chemistry Chemical Physics, vol. 7, no. 18, pp. 3297-3305, 2005.

[15] P. J. Hay and W. R. Wadt, "Ab initio effective core potentials for molecular calculations. Potentials for the transition metal atoms Sc to Hg," The Journal of Chemical Physics, vol. 82, no. 1, pp. 270283, 1985.

[16] A. D. Becke, "Density-functional thermochemistry. III. The role of exact exchange," The Journal of Chemical Physics, vol. 98, no. 7, pp. 5648-5652, 1993.

[17] C. Adamo and V. Barone, "Toward reliable density functional methods without adjustable parameters: the PBE0 model," The Journal of Chemical Physics, vol. 110, no. 13, pp. 6158-6170, 1999.

[18] S. Grimme, S. Ehrlich, and L. Goerigk, "Effect of the damping function in dispersion corrected density functional theory," Journal of Computational Chemistry, vol. 32, no. 7, pp. 1456$1465,2011$.

[19] S. Boys and F. Bernardi, "The calculation of smaller molecular intercations by the differences of separate total energies, some procedure with reduced errors," Molecular Physics, vol. 19, pp. 553-566, 1970.

[20] S. Simon, M. Duran, and J. J. Dannenberg, "How does basis set superposition error change the potential surfaces for hydrogenbonded dimers?" The Journal of Chemical Physics, vol. 105, no. 24, pp. 11024-11031, 1996.

[21] R. F. W. Bader and H. Essen, "The characterization of atomic interactions," The Journal of Chemical Physics, vol. 80, p. 1943, 1984.

[22] R. F. W. Bader, Atoms in Molecules. A Quantum Theory, Oxford University Press, Oxford, UK, 1990.

[23] R. F. W. Bader, "A quantum theory of molecular structure and its applications," Chemical Reviews, vol. 91, no. 5, pp. 893-928, 1991.

[24] H. J. Bohórquez, C. F. Matta, and R. J. Boyd, "The localized electrons detector as an ab initio representation of molecular structures," International Journal of Quantum Chemistry, vol. 110, no. 13, pp. 2418-2425, 2010.

[25] E. R. Johnson, S. Keinan, P. Mori-Sánchez, J. Contreras-García, A. J. Cohen, and W. Yang, "Revealing noncovalent interactions," Journal of the American Chemical Society, vol. 132, no. 18, pp. 6498-6506, 2010.

[26] P. Cacciani, P. Čermák, J. Cosléou, J. El Romh, J. Hovorka, and M. Khelkhal, "Spectroscopy of ammonia in the range 6626-6805 cm-1: Using temperature dependence towards a complete list of 
lower state energy transitions," Molecular Physics, vol. 112, no. 18, pp. 2476-2485, 2014.

[27] J. Andrés, S. Berski, J. Contreras-García, and P. GonzálezNavarrete, "Following the molecular mechanism for the NH3 $+\mathrm{LiH} \rightarrow \mathrm{LiNH} 2+\mathrm{H} 2$ chemical reaction: a study based on the joint use of the quantum theory of atoms in molecules (QTAIM) and noncovalent interaction (NCI) index," The Journal of Physical Chemistry, vol. 118, no. 9, pp. 1663-1672, 2014.

[28] J. Tomasi, B. Mennucci, and E. Cancès, "The IEF version of the PCM solvation method: an overview of a new method addressed to study molecular solutes at the QM ab initio level," Journal of Molecular Structure: THEOCHEM, vol. 464, no. 1-3, pp. 211-226, 1999.

[29] A. V. Marenich, C. J. Cramer, and D. G. Truhlar, "Universal solvation model based on solute electron density and on a continuum model of the solvent defined by the bulk dielectric constant and atomic surface tensions," The Journal of Physical Chemistry B, vol. 113, no. 18, pp. 6378-6396, 2009.

[30] M. J. Frisch, G. W. Trucks, H. B. Schlegel et al., Gaussian 09, Revision D.01, Gaussian, Inc, Wallingford, Conn, USA, 2013.

[31] F. W. Biegler-könig, R. F. W. Bader, and T. H. Tang, "Calculation of the average properties of atoms in molecules. II," Journal of Computational Chemistry, vol. 3, no. 3, pp. 317-328, 1982.

[32] AIMPAC, http://www.chemistry.mcmaster.ca/aimpac/imagemap/ imagemap.htm.

[33] N. Keith, Calculation of magnetic response properties using a continuous set of gauge transformations [Ph.D. Thesis], Ontario, Canada, 1993. 

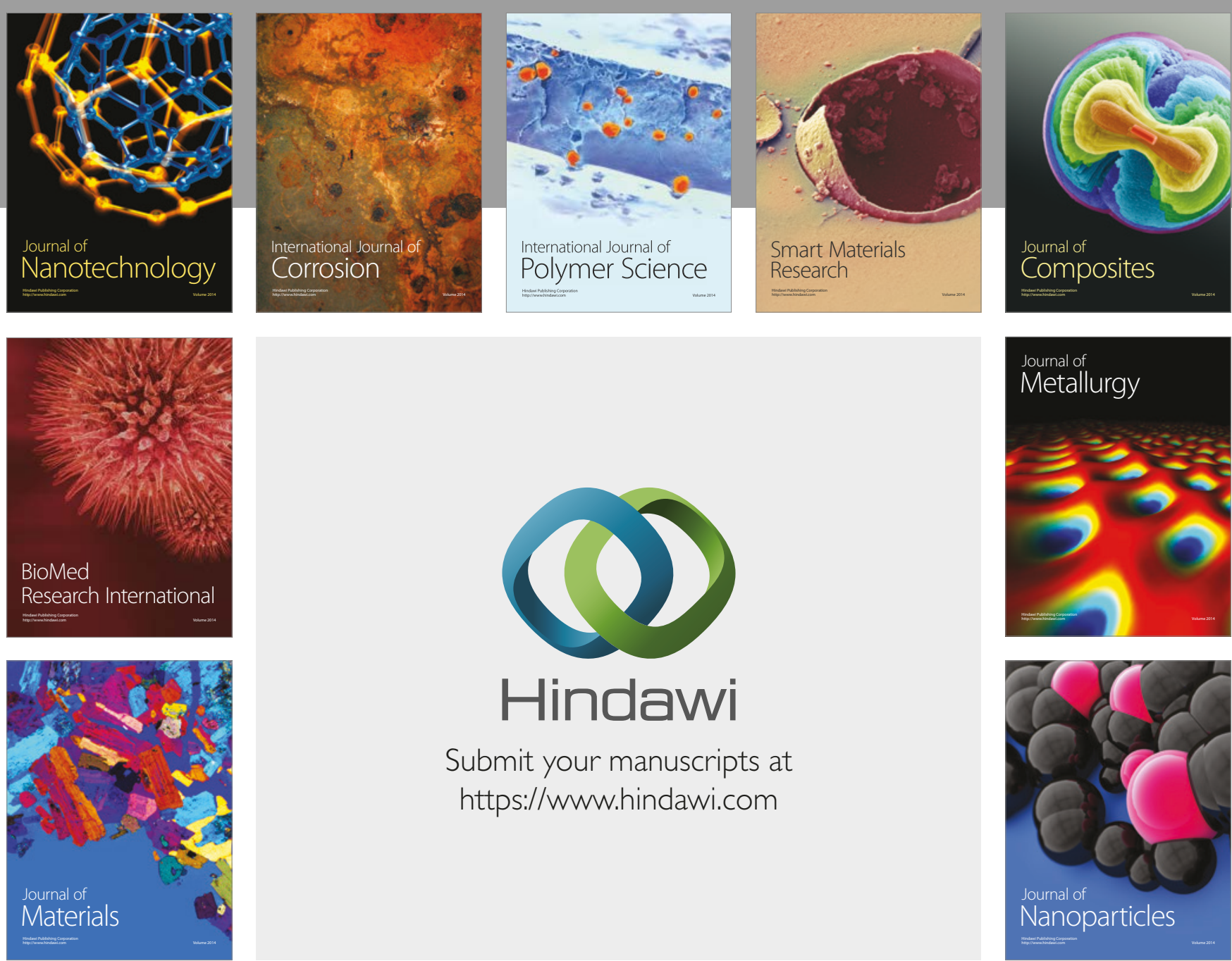

\section{Hindawi}

Submit your manuscripts at

https://www.hindawi.com
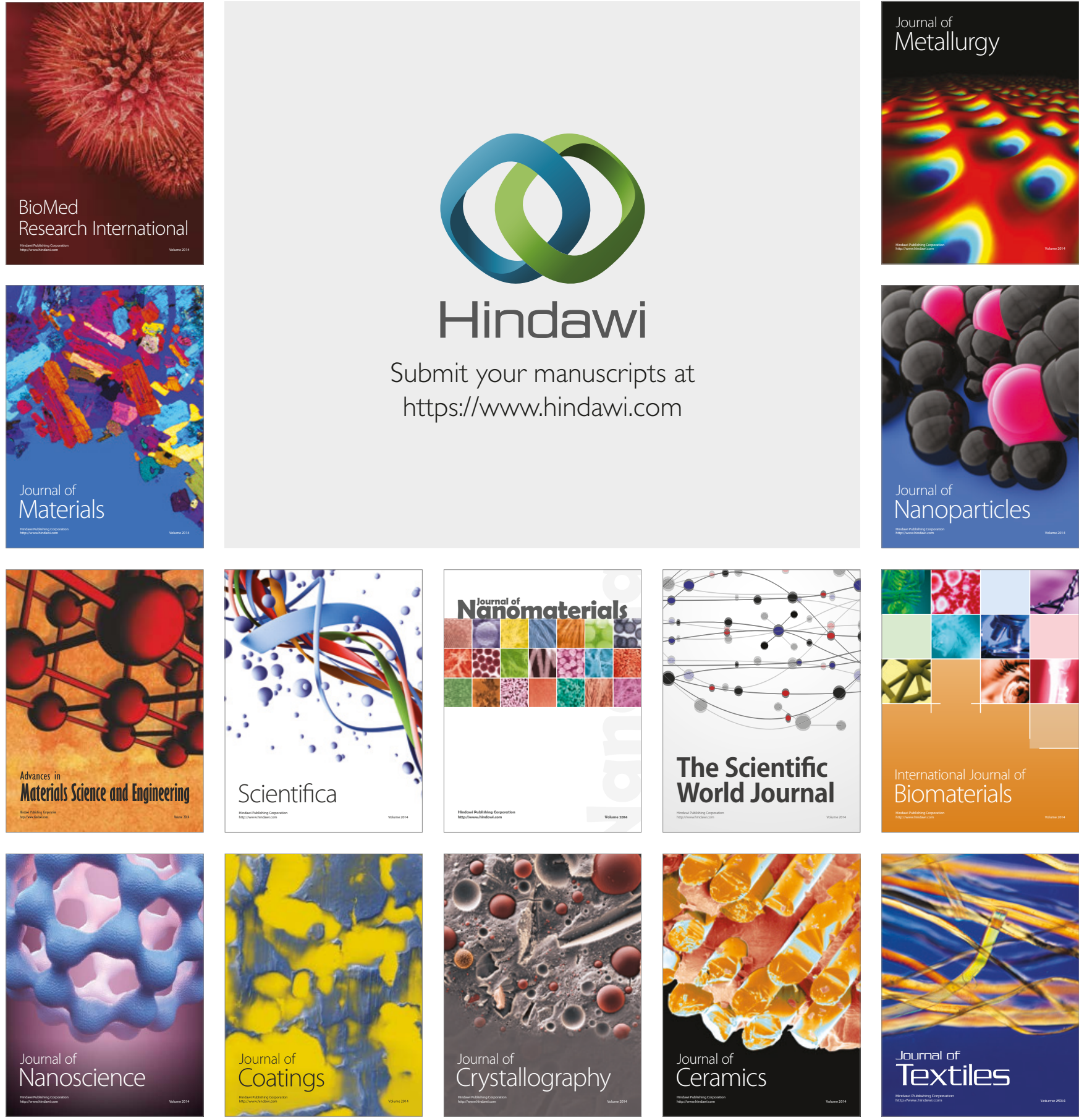

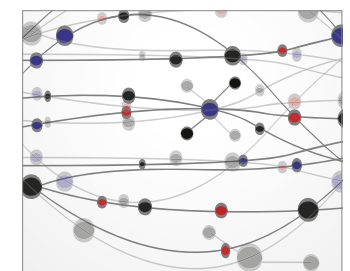

The Scientific World Journal
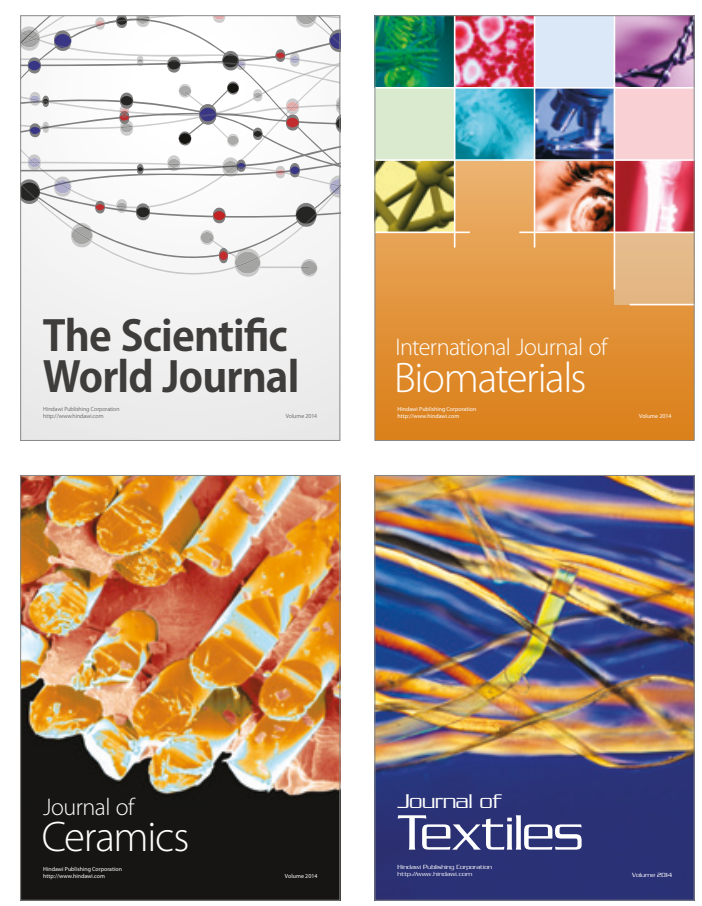